\title{
A CONSTRUÇÃO SOCIAL DO MERCADO DE MADEIRAS CERTIFICADAS NA AMAZÔNIA BRASILEIRA: a atuação das ONGs ambientalistas e das empresas pioneiras
}

\section{Marcelo Sampaio Carneiro*}

\begin{abstract}
Resumo: Este artigo analisa o processo de construção de um mercado de madeiras certificadas pelo selo do Forest Stewardship Council (FSC) na Amazônia brasileira. A certificação florestal pode ser compreendida como uma estratégia, desenvolvida a partir dos anos 90, por um conjunto de ONGs ambientalistas para tentar modificar o padrão de funcionamento da indústria mundial de madeiras. Como mostram alguns trabalhos de Sociologia Econômica, o processo de construção de um mercado requer um conjunto diverso de investimentos, de forma a permitir o estabelecimento e o funcionamento das trocas mercantis. No caso em questão, procuramos mostrar como esse processo se desenrolou, através da constituição de mecanismos de apoio à emergência da produção de madeiras certificadas e da atuação de empresas pioneiras (na obtenção do selo do FSC) no interior do campo econômico da indústria de madeiras tropicais.
\end{abstract}

Palavras-chave: Sociologia Econômica, Sociologia dos Mercados, indútria florestal, indústria e meio ambiente, ambientalismo, certificação florestal, Amazônia.

\footnotetext{
* Professor do Programa de Pós-graduação em Ciências Sociais da Universidade Federal do Maranhão (UFMA), doutor em Sociologia pela Universidade Federal do Rio de Janeiro (UFRJ).E-mail: mdscarneiro@uol.com.br

Trabalho apresentado no GT de Sociologia Econômica do XXIX Encontro Anual da ANPOCS.
} 


\section{Introdução}

A idéia de identificar com um rótulo os produtos oriundos de florestas tropicais nasceu da reflexão realizada pelas grandes ONGs ambientalistas transnacionais (Greenpeace, WWF, Amigos da Terra) sobre a eficácia das campanhas de boicote à compra desses produtos por consumidores do hemisfério Norte, realizadas nos anos 80 (Smouts, 2001). A avaliação de que o boicote levara apenas ao deslocamento do consumo para outros produtos florestais, oriundos de florestas temperadas e não isentos de problemas ambientais, estimulou essas entidades à construção de um mecanismo de incentivo ao bom manejo florestal, de um certificado (selo) que sinalizasse aos compradores de madeiras tropicais a realização de uma boa gestão florestal nas regiões produtoras.

O selo do Forest Stewardship Council (FSC) é uma norma de qualidade que atesta que a exploração feita em uma determinada unidade de manejo florestal, ${ }^{1}$ por uma empresa, um pequeno produtor ou um grupo de produtores (organizados comunitariamente ou não), é realizada segundo critérios ambientais, sociais e econômicos que se aproximam das condições de sustentabilidade.

O processo de certificação de operações florestais pelo sistema do FSC no Brasil começou nos anos 90, concentrando-se nas regiões Sul e Sudeste do País. No caso das florestas naturais na Amazônia, a primeira certificação empresarial ${ }^{2}$ ocorreu em 1997, na unidade de manejo florestal (UMF) da empresa Precious Wood Amazônia, ganhando mais força na década seguinte (Quadro 1).

Como procuraremos destacar, a implantação da certificação florestal não é uma operação simples. Ela implica um conjunto variado de investimentos, cujo objetivo último é o combate ao padrão tradicional de exploração da madeira e o apoio ao estabelecimento de uma nova modalidade de exploração florestal. No caso da exploração florestal na Amazônia, esse novo padrão está consubstanciado na adoção da tecnologia de Exploração de Impacto Reduzido (EIR) e 
no cumprimento da legislação fundiária e trabalhista vigente, itens que formam, na prática, os principais requisitos para uma empresa obter a certificação do FSC.

\section{Quadro 1 - Localização, área e ano de certificação de unidades de manejo florestal por empresas na Amazônia}

\begin{tabular}{|c|c|c|c|}
\hline Empresa/Comunidade & Localização & $\begin{array}{c}\text { Área } \\
\text { (em ha) }\end{array}$ & $\begin{array}{c}\text { Ano de } \\
\text { Certifi- } \\
\text { cação }\end{array}$ \\
\hline Precious Wood Amazônia (PWA) & Itacoatiara (AM) & $122.729,00$ & 1997 \\
\hline Gethal Amazonas & Manicoré (AM) & $40.862,00$ & 2000 \\
\hline $\begin{array}{l}\text { Juruá Florestal Ltda. (Faz. Santa } \\
\text { Marta) }\end{array}$ & Mojú (PA) & $12.000,00$ & 2001 \\
\hline $\begin{array}{l}\text { Cikel Brasil Verde S.A. (Faz. Rio } \\
\text { Capim) }\end{array}$ & Paragominas (PA) & $140.658,00$ & 2001 \\
\hline Juruá Florestal Ltda. (Faz. Arataú) & $\begin{array}{l}\text { Novo Reparti- } \\
\text { mento (PA) }\end{array}$ & $25.000,00$ & 2002 \\
\hline Precious Wood Belém Ltda. & Portel (PA) & $76.390,00$ & 2003 \\
\hline Guavirá Agroflorestal e Ind. Ltda. & $\begin{array}{l}\text { Nova Maringá } \\
\text { (MT) }\end{array}$ & $61.647,44$ & 2003 \\
\hline $\begin{array}{l}\text { Exportadora de Madeira do Pará } \\
\text { (Emapa) }\end{array}$ & $\begin{array}{l}\text { Afuá e Chaves } \\
\text { (PA) }\end{array}$ & $12.000,00$ & 2003 \\
\hline $\begin{array}{l}\text { Agroflorestal Vale do Guaporé } \\
\text { Ltda. (Madevale) }\end{array}$ & $\begin{array}{l}\text { Alta Floresta } \\
\text { D’Oeste (RO) }\end{array}$ & $4.924,00$ & 2003 \\
\hline Rohden Indústria Lígnea Ltda. & Juruena (MT) & $25.100,00$ & 2003 \\
\hline $\begin{array}{l}\text { Cikel Brasil Verde S.A. (Faz. } \\
\text { Jutaituba) }\end{array}$ & Portel (PA) & $108.241,00$ & 2004 \\
\hline $\begin{array}{l}\text { Ecolog Indústria e Comércio } \\
\text { Ltda. }\end{array}$ & Porto Velho (RO) & $22.132,00$ & 2004 \\
\hline Izabel Madeiras do Brasil & $\begin{array}{l}\text { Breu Branco e } \\
\text { Moju (PA) }\end{array}$ & $20.000,00$ & 2004 \\
\hline Orsa Florestal Ltda. & $\begin{array}{l}\text { Almeirim (PA) e } \\
\text { Laranjal do Jari } \\
\text { (AP) }\end{array}$ & $545.335,00$ & 2004 \\
\hline
\end{tabular}

Fonte: FSC Brasil. Dados para dezembro de 2004. 
A tese que procuraremos demonstrar é a de que o processo de promoção da certificação na Amazônia implica, na prática, um processo de construção do mercado de madeiras certificadas, isto é, no estabelecimento de um conjunto de dispositivos de suporte à produção e comercialização da madeira com o selo do FSC.

Dois são os atores principais para a emergência desse mercado de madeiras certificadas: um grupo de ONGs (Greenpeace, Amigos da Terra, Imazon e Imaflora) e um conjunto seleto de empresas florestais. Enquanto as primeiras são fundamentais para o trabalho de desconstrução do mercado tradicional de madeiras e para fomentar dispositivos de suporte aos empreendimentos certificados, é no campo das segundas, das empresas do setor madeireiro, que é disputado o embate central para a construção do mercado de madeiras certificadas, uma vez que a aposta da certificação só terá resultado se as principais empresas aderirem ao seu modelo de exploração florestal.

Portanto, ao contrário da explicação econômica standard que supõe o mercado como um fenômeno dado, representação formal do ajustamento entre a oferta e a demanda de produtos através do mecanismo de preços (Postel, 2003, p. 25), procuramos ressaltar em nossa análise os movimentos que se encontram na gênese do mercado de madeiras certificadas, bem como os obstáculos que se interpõem à sua constituição. ${ }^{3}$ Isto é, tentamos colocar em relevo os aspectos que a nova Sociologia econômica (Swedberg, 1994; Steiner, 1999) remarca, diante das insuficiências da teorização econômica convencional. Como sublinha R. Boyer:

[...] a maior parte dos economistas consideram que o mercado é a solução aos problemas de coordenação entre agentes interdependentes quando para as ciências sociais a constituição do mercado é o problema que se impõe à análise. Função e funcionamento do mercado em um caso, emergência e construção do outro: as pesquisas econômicas postulam um mecanismo central, 
do qual elas não fornecem a teoria, ainda menos a origem, ao passo que os trabalhos de Sociologia Econômica realizam uma análise da gênese dos mercados. (Boyer, 2003, p. 68).

A hipótese que orientou nossa investigação sugere que o êxito da certificação florestal na Amazônia está diretamente relacionado com a capacidade das empresas certificadas modificarem o padrão de funcionamento do setor madeireiro regional, segundo os mecanismos de transformação dos campos econômicos sugeridos por Bourdieu (1997, 2000) e Fligstein (2001). A não concretização desse objetivo pode implicar, como sugerem análises sobre o funcionamento de um marché à prescripteur ${ }^{4}$ (Hatchuel, 1995), tão-somente na formação de um monopólio ou um oligopólio, como um segmento dentro do mercado de madeiras tropicais.

Nas duas seções que seguem descrevemos: (i) a atuação das ONGs ambientalistas no processo de construção de dispositivos favoráveis ao desenvolvimento da certificação; e (ii) a trajetória de quatro empresas (Precious Wood, Gethal, Cikel e Juruá Madeiras) que foram as primeiras a obterem a certificação do FSC na Amazônia. $\mathrm{Na}$ terceira e última parte do artigo, destacamos as questões que envolvem a construção social do mercado de madeira certificada e indicamos algumas tendências sobre o desenvolvimento desse mercado, procurando identificar suas repercussões para o futuro da indústria de madeiras tropicais na Amazônia.

\section{O mercado de madeiras certificadas em construção: a atuação das ONGs ambientalistas}

Nesta seção descrevemos algumas ações desenvolvidas por um grupo específico de ONGs, classificadas como ambientalistas (Buclet, 2002), no processo de promoção da certificação florestal na Amazônia. O esforço dessas organizações será orientado 
para a construção de uma representação favorável à proposta da certificação, defendida enquanto instrumento capaz de intervir positivamente na mudança do padrão tradicional, e para a criação de diversos dispositivos (fontes de financiamento, legislação favorável, mecanismos de transferência de tecnologia, etc.) necessários ao desenvolvimento da produção certificada.

Os dois processos que descreveremos em seguida, a construção do grupo de compradores de madeira certificada e o processo de difusão da tecnologia da EIR, não esgotam o leque de iniciativas que estão na base da difusão da certificação na Amazônia (Carneiro, 2004, p. 134), mas, oferecem-nos uma amostra dos investimentos realizados no processo de construção do mercado de madeiras certificadas.

Construindo a demanda para a madeira certificada: o desenvolvimento do grupo de compradores de produtos com o selo do FSC no Brasil

O Grupo de Compradores de Madeira Certificada (posteriormente renomeado para Grupo de Compradores de Produtos Florestais Certificados), seção brasileira da rede global de comércio e floresta, foi fundado em abril de 2000. Sua constituição foi resultado da atuação das ONGs integrantes da parceria denominada "Aliança para o consumo sustentável”, Imaflora, Imazon e Amigos da Terra, cabendo a esta última um papel mais direto na condução do grupo.

A necessidade do desenvolvimento de iniciativas para tentar organizar uma atuação no mercado interno de madeiras no Brasil é uma preocupação que antecede a criação do grupo de compradores. Destarte, já em 1997, no trabalho "Garimpagem Florestal: relatório atualizado sobre a extração ilegal de madeira na Amazônia brasileira”, a ONG Amigos da Terra esboçava um programa de atuação nesse sentido. 
Em 1998, o Imaflora firmou parceria com a Amigos da Terra e deu novo formato ao seu Programa de Apoio à Comercialização de Produtos Certificados, passando a trabalhar junto a setores produtivos enquanto à outra $\mathrm{ONG}$ coube "as atividades relacionadas com a divulgação junto aos consumidores finais" (Imaflora, 2000, p. 56). Além dessa nova divisão de trabalho, a entidade decidiu realizar um estudo detalhado do funcionamento do mercado de madeira na região centro-sul do Brasil, para tanto, procurou o Imazon, ONG sediada na Amazônia, que dispunha de savoir-faire mais adequado à realização da análise.

Contudo, o passo mais concreto para impulsionar a construção do grupo ocorreu em outubro de 1999, com a realização em Manaus (AM), do "I Workshop Produção Sustentável de Madeira na Amazônia: oportunidades de negócio". Esse evento, articulado pelo Banco Mundial com o apoio do Imaflora, Imazon, WWF e Amigos da Terra reuniu, pela primeira vez, os principais atores do mercado de madeiras tropicais - indústria madeireira, consumidores de madeira, instituições financeiras (públicas e privadas), governos estaduais da região, governo federal - para a discussão de uma agenda que viabilizasse o manejo sustentado e a certificação florestal em larga escala na região.

O encontro foi organizado visando à confluência das discussões para dois temas: a) a constituição do grupo de compradores; e, b) a atuação conjunta em face do problema do financiamento para a indústria madeireira. Dessa reunião nasceu o embrião do grupo de compradores, com a ONG Amigos da Terra assumindo sua coordenação.

Como parte da estratégia acertada pelas ONGs da "Aliança para o consumo sustentável", foi publicado o estudo Acertando o Alvo (Smeraldi; Veríssimo, 1999), que pode ser considerado 
como um marco na trajetória que levou à constituição do grupo de compradores de madeira certificada. Para tanto, esse trabalho cumpriu duas funções: a) identificou o mercado interno brasileiro (especialmente o de São Paulo) como o principal destino da madeira oriunda da Amazônia; e, b) esboçou um plano de atuação para a promoção da certificação junto a determinados segmentos desse mercado.

Em 2001, o mesmo conjunto de entidades realizou um outro estudo, denominado Acertando o Alvo 2, no qual avaliam o potencial para a compra de madeira certificada no mercado de São Paulo (Sobral et al., 2002). Através dessa publicação, cujo caráter prescritivo é evidente, seus autores procuram reforçar a tese da possibilidade da promoção da certificação no mercado interno brasileiro, ponto sobre o qual a introdução ao estudo é incisiva:

"Existe o mito de que o mercado brasileiro de madeiras amazônicas não tem interesse em adquirir produtos florestais certificados. Este levantamento inédito realizado em 2001 no Estado de São Paulo, (...), revela uma situação surpreendente: há uma demanda para madeira certificada de aproximadamente $20 \%$ (...) do volume total consumido no Estado" (Sobral, et al., 2002, p. 7).

Desde a sua fundação, o grupo de compradores vem conseguindo ampliar o seu quadro de associados. De acordo com dados disponíveis, cem entidades participam atualmente do grupo (Azevedo, 2005, p.26). Nos últimos anos, o grupo de compradores vem investindo na promoção de feiras de produtos florestais certificados, já tendo realizado duas, em 1994 e 1995, no Estado de São Paulo. As feiras, além da importância para divulgação da proposta de certificação, possuem papel destacado no estabelecimento de relações entre as empresas que operam nos dois lados (oferta e demanda) do mercado de produtos certificados. 
A formação da base técnica para a expansão da certificação: o trabalho do Imazon e da Fundação Floresta Tropical

A certificação do FSC adota a noção de "bom manejo florestal", termo utilizado para designar operações que trabalham segundo padrões aceitáveis da técnica de exploração de florestas tropicais (Viana, 2002, p. 19), e que na prática das empresas certificadas significa a adoção da tecnologia da Exploração de Impacto Reduzido (EIR). ${ }^{5}$

Como diversos analistas registraram (Dykstra, 2001; Blate et al., 2001), um dos principais entraves ao desenvolvimento da EIR tem sido a ausência da geração de conhecimento local sobre sua aplicação e de pessoal qualificado para executá-la. No caso da Amazônia brasileira essas deficiências começaram a ser supridas a partir do início dos anos 90 , com as pesquisas levadas a cabo pelo Imazon e pela constituição de centros de treinamento e de transferência de tecnologia da Fundação Floresta Tropical.

Esse caráter aplicado do conhecimento produzido pode ser considerado como uma das marcas da atuação do Imazon (Buclet, 2002, p. 7). As pesquisas iniciais do Imazon foram focalizadas no estudo dos usos dos recursos naturais em regiões de forte atividade madeireira com um olhar especialmente voltado para a análise das técnicas de extração de madeira e das práticas silviculturais pósexploratórias.

Um dos primeiros trabalhos da entidade sobre a extração madeireira, publicado em 1992, procurou demonstrar as vantagens da introdução de algumas medidas do repertório de técnicas preconizado pelo método da EIR quando comparadas com a exploração convencional. A conclusão do estudo apontou que a introdução de "técnicas simples de manejo poderia levar a um aumento substancial na acumulação do volume de madeira comercial" e que os lucros das empresas madeireiras da região eram suficientes para arcar com os 
custos da realização do manejo florestal (Veríssimo et al., 1996, p. 31-33).

Embora essa atuação do Imazon na difusão das técnicas da EIR tenha sido importante, ela apresentava limitações evidentes, visto que a adoção pelas empresas das indicações geradas pelas pesquisas demandaria um esforço mais consistente do que a publicação de um manual de práticas florestais, exigindo, como veremos a seguir, um programa de formação de profissionais do setor, tarefa que foi assumida e executada pela Fundação Floresta Tropical (FFT).

A FFT começou a operar na Amazônia em 1994, trabalhando numa área de mil hectares cedida pela empresa Cikel Brasil Verde. A partir dessa unidade, a Fundação realiza atividades de promoção e disseminação de tecnologias de manejo de florestas tropicais, com ênfase especial na implantação de modelos de exploração de impacto reduzido (FFT, 2000).

A estratégia de difusão da tecnologia de EIR da FFT inclui um variado leque de instrumentos: cursos que são realizados nas áreas da Fundação; treinamentos in situ, com a demonstração da tecnologia da EIR diretamente nas áreas das empresas; estágios para estudantes de nível médio e superior; dias de campo, instrumento tradicional da prática extensionista para processos de transferência de tecnologia, além de incluir a elaboração e divulgação de publicações e vídeos sobre o tema.

Uma forma de verificar a eficácia da atuação da FFT, e de medir a penetração da difusão das técnicas de EIR, é examinar o público que participa dos seus treinamentos. No caso dos cursos realizados nessa primeira fase, que corresponde ao período de 1996 a 1999, o grupo que apresentou maior número de participantes foi o de alunos de instituições de ensino florestal, vindo em seguida técnicos de instituições estaduais de meio ambiente, técnicos de 
instituições de pesquisa não-governamentais e representantes da indústria madeireira.

A presença relevante de representantes da indústria madeireira entre os atingidos pelos cursos é outra meta visada pela FFT, haja vista a importância do segmento para a adoção da EIR. O repasse dessa tecnologia pode ser compreendido como uma transferência de recursos (subsídio) para as empresas florestais, que, só passam a adotar essa tecnologia a partir do conhecimento de eficácia operacional e das economias de custo que ela propicia (Blate et al., 2001, p. 9).

\section{O mercado de madeiras certificadas em construção: a trajetória das empresas pioneiras}

O outro componente central do processo de construção do mercado de madeiras certificadas refere-se à sua adoção pelas empresas do setor florestal. Nesta seção, tomamos para análise a trajetória das quatro primeiras empresas certificadas - Precious Wood Amazon, Gethal Amazonas, Juruá Florestal e Cikel Brasil Verde.

Essas firmas são compreendidas aqui como empresas pioneiras (desafiadoras), pois ao adotarem as práticas exigidas pela certificação (EIR, legalidade das operações florestais, etc.), elas estão concorrendo para modificar o padrão de funcionamento da produção de madeiras tropicais na Amazônia, mudando, por conseguinte, o campo econômico em que se encontram inseridas. ${ }^{6}$

Como tentaremos demonstrar através da análise da trajetória dessas firmas, estamos diante de empresas com um padrão de atuação diferente vis-à-vis o campo da indústria madeireira na Amazônia. Portanto, nosso interesse nas seções que seguem é o de desvelar os motivos e as condições que levaram essas empresas a optarem pelo caminho da certificação, através da análise de sua colocação 
no "espaço de posições e de trajetórias" (Lebaron, 2000, p.65), de forma a compreender seu posicionamento no campo das empresas florestais da Amazônia.

O primeiro investimento "socialmente responsável" no setor florestal da Amazônia: a trajetória do grupo Precious Wood

O grupo Precious Wood (PW) é uma empresa de investimentos, organizada sob o formato de holding, que foi constituído por "um grupo de empresários suíços que, preocupados com a destruição de florestas tropicais, queriam criar modelos de produção florestal sustentável” (Clay \& Amaral, 2002, p. 164).

O primeiro investimento do grupo foi num projeto de reflorestamento na Costa Rica, em 1990, e, quatro anos depois, o grupo PW comprou 80 mil hectares de terra em Itacoatiara, principal pólo de produção madeireira do Amazonas, e dava a largada para suas operações no Brasil com a constituição da empresa Precious Wood Amazônia (PWA). Pensada sob a forma de um "econegócio", a implantação do projeto de Manejo Florestal Sustentável da PWA logo se desvencilharia dos cânones tradicionais da exploração florestal na Amazônia, adotando o método de exploração de impacto reduzido e optando pela certificação florestal.

Para Carmino e Alfaro (1998), a obtenção do selo do FSC teve um papel importante para a estratégia da empresa, uma vez que ele confirmaria o compromisso desta com o manejo florestal praticado de forma sustentável, sinalizando positivamente para seus acionistas, para a opinião pública da Suíça e para a Agência de Cooperação Suíça, que lhe deu significativa assistência política e financeira.

Do ponto de vista do desempenho econômico da empresa, dois aspectos sobressaem: o montante do capital investido (diante do 
padrão da indústria madeireira regional) e o período em que a empresa ficou sem resultados operacionais positivos - somente em 1999 o valor da produção conseguiu se equiparar aos custos operacionais da empresa (Precious Wood, 2001, p. 9). Essas informações deram margem ao surgimento do argumento, esgrimido pelos setores tradicionais da indústria madeireira, de que o empreendimento não possuía fins lucrativos, tratando-se de recursos da "previdência social de velhinhos suíços" (Benchimol, 1998, p. 115), cujo alvo efetivo era a viabilidade ou não da realização de uma exploração florestal assentada na legalidade (fundiária, ambiental e trabalhista) e nos padrões da EIR.

Como o volume de madeira extraída na área inicialmente adquirida se revelará insuficiente para fazer frente às metas de produção estabelecidas no plano de manejo (30 mil metros cúbicos/ ano), o grupo realizou mais dois investimentos em recursos fundiários, adquirindo 42 mil hectares em 2001 (Precious Wood, 2003, p. 9) e 75 mil hectares em 2003.

Contudo, a expansão do grupo não ficará restrita ao estado do Amazonas. Ainda em 2002, o grupo Precious Wood se juntará ao importador holandês A. van den Berg (maior comprador da produção da empresa na Europa) para a aquisição de uma serraria em Belém (PA) - da firma Lisboa Madeiras Ltda. - e 45,738 mil hectares de terra no município de Portel (PA), para dar início a outro projeto de manejo florestal (Smartwood; Imaflora, 2002, p. 4). Consoante com a filosofia do grupo, a Lisboa Madeiras Ltda. entrará rapidamente no processo de certificação, cumprindo os requerimentos exigidos e recebendo o selo do FSC em março de 2002.

O aspecto pioneiro da atuação da Precious Wood na exploração florestal na Amazônia, ao mesmo tempo em que impôs a mobilização de uma grande quantidade de recursos e que demandou um tempo de espera para os primeiros resultados positivos, também lhe trouxe 
benefícios, com a ocupação pelo grupo de um espaço privilegiado no mercado europeu de madeiras tropicais. Nas palavras do seu diretor florestal: "O fato de ser certificado FSC nos conferiu uma situação de monopólio sobre um grande número de mercados, sobretudo na Suíça, na Alemanha e nos países do Benelux" (WWF-Suisse, 2002, p.3).

O ano de 2001 marcou a entrada do grupo na bolsa de valores da Suíça, com a colocação de cem mil novas ações para venda, operação que possibilitou a captação de cerca de 8,6 milhões de dólares. A captação desses recursos permitiu a ampliação do desenvolvimento da Precious Wood na Amazônia, incorporando novas áreas, e confere razão ao enunciado mercantil adornado de roupagem ecológica que consta no relatório anual de 2001 do grupo:

[...] se o manejo florestal de Precious Wood continuar crescendo, mais florestas poderão ser compradas e salvas do ultimato da destruição. Quanto antes melhor. Contudo, duas condições devem ser reunidas: Precious Wood deve apresentar um maior sucesso econômico no futuro e Precious Wood deve também se preocupar em apresentar seu modelo de negócio para o mercado de capitais de maneira convincente. (Precious Wood, 2002, p. 11, grifo nosso).

Esse apelo à ampliação do investimento da empresa na Amazônia vem acompanhado de um inteligente trabalho de publicidade da marca da empresa (sorteio de viagem à unidade de manejo florestal em Itacoatiara, no Estado do Amazonas), ocupação de espaços na mídia, etc. Na capa do seu Relatório Anual de 2001, o grupo Precious Wood exibe, através de uma imagem de satélite, uma amostra do resultado de sua atuação na Amazônia brasileira: a manutenção da integridade florestal na área adquirida para a implantação do manejo florestal da empresa Precious Wood no Pará, o que denota o efeito performativo buscado com a utilização da imagem de empresa ambientalmente responsável. 
A certificação como condição para a compra de uma empresa: o caso da Gethal Amazonas S/A

A trajetória do grupo Gethal na Amazônia começou no início dos anos 70, com o deslocamento de uma unidade de laminação do Rio Grande do Sul, estado de origem do grupo, ${ }^{7}$ para o município de Itacoatiara (AM). Na década seguinte, o grupo incorporou os compensados à sua linha de produção e se tornou a maior empresa do setor madeireiro no Amazonas.

Em 1998, a Gethal Amazonas S/A se dissociou da matriz gaúcha e passou a ter uma nova organização societária, dividida entre a empresa alemã Westlag \& Gethalit (25\% das ações) e o grupo Nilorey (75\%), controlado pelo empresário Bruno Stern (Smartwood; Imaflora, 2000, p. 5).

A partir desse momento, a empresa - que vinha enfrentando sérias dificuldades desde o estabelecimento do Plano Real, com os reflexos da apreciação cambial sobre os custos internos e as vendas externas da empresa - passou a ser preparada para venda, tendo na certificação um elemento central nessa estratégia. Segundo Zimmermann (2001, p. 20), a mudança na diretoria coincide de certa forma com a procura de estratégia de sobrevivência da empresa, que foi, por um lado, pressionada pelo Ibama por estar comprando madeira de fornecedores ilegais e, de outro, pelos compradores de madeiras tropicais na Europa.

Em 1999 começaram as negociações para a transferência do controle acionário da empresa ao fundo de investimento norteamericano Brazilian Forestry Fund Investments (BFFI), administrado pelo grupo Grantham, Mayo, Van Otterloo \& Co., que, contudo, exigiu a certificação do manejo florestal como uma pré-condição para o fechamento do negócio. Por conseguinte, a opção da certificação, além de estar no horizonte da empresa por sua forte dependência do mercado externo, findou por tornar-se um imperativo para a sua sobrevivência. 
A primeira certificação conseguida pela Gethal Amazonas S/A foi a de cadeia de custódia, atribuída em 1999 pelo Imaflora/ Smartwood. A certificação de uma unidade de manejo florestal própria ocorreu no ano seguinte, com a avaliação e aprovação do selo do FSC para uma área de 48.862,00 hectares, localizada no município de Manicoré no Estado do Amazonas (Smartwood; Imaflora, 2000, p. 5).

Após a certificação, a Gethal manifestou a intenção de dar continuidade aos investimentos planejados, o que incluía: i) a certificação de mais 20 mil hectares na região de Manicoré; ii) a ampliação da produção da fábrica, de 26.400 para 33.000 metros cúbicos em 2001; e, iii) a construção de uma termelétrica para aproveitar os resíduos da produção madeireira. Entretanto, ano após ano, os resultados da empresa se mostraram menos promissores.

Em 2002, a Gethal teve seu pior desempenho desde o início dos anos 90, reduzindo seu efetivo de trabalhadores em cerca de $70 \%$ (Smartwood, 2002b, p. 59). O último relatório de monitoramento da certificação da empresa, realizado em dezembro de 2003, registrou sua difícil situação:

O ano de 2003 foi decisivo para a continuidade das atividades florestais da Gethal. Após vários anos marcados pelo baixo rendimento financeiro e por dificuldades na gestão administrativa dos recursos investidos, no início de 2003 o grupo norte-americano de investimentos GMO-RR considerou perdido o investimento inicial de US\$ 20 milhões e cogitou o fechamento da empresa. (Smartwood; Imaflora, 2004, p. 3).

Em 2005, alegando dificuldades com o Ibama para obter as licenças necessárias à realização da atividade de exploração florestal, a empresa fechou suas portas e, em 2006, foi vendida pelo fundo de investimento GMO para um empresário sueco pela quantia de R \$ 30 milhões. Segundo as declarações publicadas na imprensa, o novo proprietário dos ativos florestais da Gethal não pretende 
dar continuidade à exploração florestal, o que significa o fim dessa experiência de certificação.

Uma empresa familiar em transição para o Manejo Florestal Sustentável: a certificação da Cikel Brasil Verde S/A

A empresa conhecida como Cikel Brasil Verde S/A iniciou sua trajetória na Amazônia nos anos 70, a partir de uma unidade de processamento de madeira serrada implantada no então município de Imperatriz, no Estado do Maranhão. Seguindo o padrão vigente da exploração madeireira na Amazônia Oriental, a empresa participou do processo de esgotamento dos recursos florestais regionais - de forma similar a um movimento de acumulação primitiva - até se deslocar, no fim dos anos 90, para o estado do Pará, em busca de novas fontes de matéria-prima.

Em 2004, a Cikel possuía seis unidades industriais: três serrarias, uma laminadora, uma fábrica de pisos e uma indústria de compensados e laminados. Para abastecer esse conjunto industrial, a empresa possui cerca de 500 mil hectares de florestas, dos quais 206 mil de áreas próprias, localizadas no município de Paragominas (PA) e mais 300 mil hectares arrendados de outras empresas (Almeida, 2002, p. 27).

Conforme noticiado no site da empresa, o envolvimento da Cikel com a certificação está relacionado com a parceria estabelecida com a FFT, em 1995. Na oportunidade, a empresa cedeu uma área para a FFT que começou a desenvolver atividades de treinamento e pesquisa sobre a exploração florestal de baixo impacto. Além dessa parceria, vale a pena ressaltar o envolvimento da empresa, em 1999, no projeto PD 7/94 da ITTO, para transferência de tecnologia visando aumentar o comércio de madeira tropical oriunda de fontes sustentáveis entre o Brasil e países selecionados da Europa e dos Estados Unidos (Delespinasse, 2002, p. 1). 
Além da influência positiva das relações estabelecidas com organizações como a FFT e com projetos como o acima citado, a trajetória da Cikel para a certificação confirma uma das tendências apontadas por Stone (2000, p. 30) para a indústria madeireira em Paragominas, que é o aumento do investimento em terras e capital e um maior foco na exportação, o que, segundo nosso ponto de vista, torna essas empresas mais inclinadas ao tema da ecocertificação.

De acordo com informação da Cikel, o processo de certificação custou US\$ 600 mil e os gastos com a adequação ao novo padrão de exploração florestal, particularmente os referentes à mão-de-obra, foram bem absorvidos pela empresa. Os custos com a força de trabalho teriam se elevado em $12 \%$, mas, em contrapartida, a produtividade dos trabalhadores teria crescido $30 \%$, contrabalançando a referida elevação. Ademais, com a introdução da exploração de impacto reduzido - um requerimento da certificação - a empresa obteve ganhos na redução do desperdício da extração da madeira e nos gastos com a manutenção dos equipamentos.

No front da comercialização, a empresa vem obtendo ganhos significativos, o que deve ser associado a três fatores: i) sobrepreço obtido com a certificação, que, para algumas espécies mais nobres, teria alcançado a casa dos 50\%; ii) captura de mercados internacionais importantes, como o holandês (do qual a empresa responderia por $17 \%$ das importações de madeiras tropicais); iii) verticalização de sua produção, com o investimento de US\$ 3,5 milhões, realizado em 2000, na fábrica de Ananindeua (para a produção de pisos e decks), o que conferiu um novo perfil à exportação da empresa, agregando maior valor aos produto comercializados.

A certificação como ponto de ruptura na trajetória de um grupo empresarial: o caso da Juruá Florestal Ltda

Primeira empresa de capital inteiramente nacional a obter certificação do FSC para uma unidade de manejo florestal, a Juruá 
Florestal Ltda. possui sua trajetória vinculada aos empreendimentos da família Peracchi na indústria madeireira do Pará. A empresa foi constituída em 1992 com o nome de Juruá Madeiras Ltda., com sede no município de Tucumã (PA), tendo como fundadores Idemar Peracchi (detentor de $80 \%$ das quotas-partes), também sócio majoritário da Exportadora Peracchi Ltda., e Ana Valéria J. Peracchi, esposa de Idacir Peracchi.

Em 1999, numa operação simultânea, Idacir Peracchi se desfez de suas ações na Exportadora Peracchi (cerca de 19\% do total), vendendo-as a Idemar Peracchi e seus filhos. Este, por sua vez, se retirou da Juruá Madeiras Ltda., vendendo suas quotas no empreendimento para Idacir Peracchi que, junto com a esposa, assumiu o comando da empresa e, a partir desse momento, passaram a desenvolver açõe, no sentido de orientar a Juruá para a obtenção da etiqueta do FSC.

O aspecto interessante do acompanhamento dessa transferência patrimonial interna na família Peracchi está no fato de que a Exportadora Peracchi - uma das maiores firmas exportadoras de madeira serrada do Brasil nos anos 90 (Macedo et al., 1997, p. 164) - tem seu nome associado às práticas de extração ilegal de madeira, enquanto que a Juruá Florestal se encaminhou, a partir da referida mudança patrimonial, para a exploração florestal certificada. Esse processo teria ocorrido em meio a conflitos no interior da família Peracchi (SCS, 2001, p. 12), conferindo à empresa uma trajetória singular no conjunto do setor madeireiro na Amazônia.

Uma explicação possível para a decisão de Idacir Peracchi se retirar da Exportadora Peracchi e constituir sua própria firma de produção e comercialização de madeiras está relacionada com a sua experiência à frente dos negócios florestais da companhia, posição que lhe permitiu acompanhar de perto as dificuldades da empresa para acessar os mercados internacionais de madeira tropical, cada vez mais sensíveis à questão da origem do produto florestal. 
De forma similar ao ocorrido com a Cikel Brasil Verde, a Juruá também contou com o apoio importante de instituições de pesquisa e de transferência de tecnologia na passagem para a exploração florestal certificada, no caso do aporte técnico-financeiro do Projeto PD 7/94 do Sindimade/ITTO e da colaboração estabelecida com a Embrapa-Cifor, através do projeto "Bom manejo: Manejo sustentável de florestas na Amazônia brasileira”.

As atividades do projeto "Bom Manejo" visaram preparar as empresas para a adoção das técnicas de exploração de impacto reduzido, contudo, na perspectiva da Juruá, a participação no projeto esteve diretamente relacionado com a meta da obtenção da certificação florestal, como bem destacou estudo realizado por Pokorny e Sousa (2000, p.68).

Em junho de 2003, por ocasião do Seminário “Certificação Florestal na Amazônia: avanços e oportunidades", a Juruá tornouse a primeira companhia a obter recursos do Profloresta, uma linha de crédito criada pela mobilização das entidades envolvidas na promoção da certificação junto ao Banco da Amazônia S/A (Basa).

\section{Conclusão: o mercado é verde?}

O mercado de madeiras certificadas ainda representa parcela pequena do conjunto da madeira comercializada oriunda de florestas naturais da Amazônia - cerca de 1,7\%, segundo a ONG Amigos da Terra (Smeraldi, 2002, p. 10). Todavia, apesar dessa participação reduzida, o montante da área de unidades de manejo florestal certificadas por empresas vem apresentando crescimento constante, passando de 122 mil hectares, em 2000, para cerca de 1.220 .000 hectares até o fim de 2004.

Outra característica desse emergente mercado de madeiras certificadas diz respeito à sua concentração no segmento das médias 
e grandes empresas da indústria madeireira sediada na Amazônia. Quando analisamos o porte (segundo o número de empregados) das empresas, verificamos que salvo uma única exceção - a Madeireira Vale do Guaporé Ltda. - todas as firmas certificadas se situam no estrato das médias e grandes empresas do setor, que, representando apenas $3 \%$ do total de empresas da região, respondem por $27 \%$ do emprego formal gerado (Carneiro, 2004, p. 237).

Com base na descrição da trajetória das quatro primeiras empresas a receberem o selo do FSC na Amazônia, o caminho das firmas para a certificação pode ser bem compreendido à luz da teoria dos campos econômicos. Como sugere essa abordagem, a explicação para a modificação na estratégia de uma dada empresa deve ser procurada através da análise do campo econômico no qual ela se encontra inserida, da identificação da posição que ela ocupa no interior desse campo e dos capitais de que ela dispõe para enfrentar as empresas concorrentes.

No caso das empresas tradicionais do setor, considerando os exemplos da Cikel Brasil Verde S/A e da Juruá Florestal Ltda., o processo de mudança se aproxima do modelo sugerido por Fligstein (2001, p.76), em que a direção da empresa identifica uma situação de crise/mudança no campo econômico e passa a adotar uma nova estratégia com vistas a reorientar a atuação da firma no setor.

No exemplo da Juruá Florestal Ltda., esse processo ocorreu em meio a uma ruptura no seio do grupo familiar, com a separação dos dois principais acionistas das empresas da família Peracchi, um permanecendo nos marcos da exploração tradicional (Exportadora Peracchi S/A) e outro optando pelo ingresso no mercado de madeiras certificadas (Juruá Florestal Ltda.). Já no exemplo da Cikel Brasil Verde S/A, esse movimento foi menos traumático, estando muito associado à relação privilegiada que essa empresa estabeleceu com a ONG responsável pela difusão da tecnologia da EIR na Amazônia, a Fundação Floresta Tropical. 
A trajetória das empresas Mil Madeireira e Gethal Amazônia, adquiridas, respectivamente, pelos grupos Precious Wood Management Ltd. e Grantham, Mayo, Van Oterlloo \& Co., aponta para um processo diferente, próximo da situação apontada por Bourdieu (1997, p. 58), na qual as empresas desafiadoras são oriundas de outros campos econômicos, com uma dotação de capitais diferenciada. Como já sublinhamos, essas empresas foram compradas por fundos de investimento institucionais que possuem um lastro de recursos financeiros muito superior ao mobilizado pelas indústrias tradicionais do setor madeireiro amazônico.

O exemplo dessas quatro empresas mostra também como a aquisição de um determinado tipo de capital - no caso em questão, o capital simbólico associado à proteção das florestas tropicais -, pode ser utilizado para alavancar a acumulação de outros tipos de capitais (financeiro, comercial). Esse processo de conversão de capitais é exemplarmente ilustrado na trajetória do grupo Precious Wood, cuja obtenção do selo do FSC foi a condição para a mobilização de capital financeiro (atração de investidores institucionais, expansão posterior via venda de ações) e de capital comercial (ocupação de determinada parcela do mercado europeu de madeira tropical).

A análise das trajetórias empresariais aponta para uma outra característica comum ao conjunto das empresas certificadas: sua relação privilegiada com as organizações promotoras do mercado de madeiras certificadas (ONGs, agências de cooperação internacional, instituições de apoio a difusão da tecnologia de EIR). Por conseguinte, o processo de certificação de cada uma dessas empresas esteve associado a algum tipo de acesso a financiamentos institucionais ou a subsídios diretos e indiretos, como o treinamento da força de trabalho nos cursos da FFT e a contratação de profissionais formados pelo curso de Pós-Técnico Florestal.

Como tem sublinhado a literatura sobre o processo de construção social de mercados, o estabelecimento de novas relações 
mercantis entre um conjunto de atores é o resultado de investimentos visando à destruição das relações sociais que sustentavam o mercado até então estabelecido e a promoção de novos dispositivos, voltados para o fomento do novo padrão de produção, comercialização e consumo (Garcia, 1986; Ughetto, 2003; Callon \& Muniesa, 2003).

Consoante essa linha de interpretação, podemos descrever o processo de implantação do mercado de madeiras certificadas na Amazônia como o resultado de dois movimentos: i) do trabalho de crítica (Boltanski \& Chiapello, 1999) ao mercado tradicional de madeiras $^{8}$ e, ii) do conjunto de investimentos para a promoção da produção e o consumo de madeiras portadoras do selo do FSC.

A observação da implantação desses conjuntos de dispositivos visando estruturar o mercado de madeiras certificadas faz emergir um outro dado: a importância do estabelecimento de relações entre dirigentes e técnicos de ONGs, de empresas e do Estado (Ministério do Meio Ambiente, Ibama), no processo de promoção da certificação florestal.

Nos casos aqui apresentados são muitos os exemplos que confirmam essa importância, destarte, um diretor da Gethal explicou a solução encontrada para o problema da aquisição de equipamentos para a atividade de exploração florestal junto à empresa Caterpillar: "graças à participação tanto da Gethal quanto da Caterpillar na FFT, o que ressalta, segundo ele, a importância da participação em todos os organismos nacionais e internacionais possíveis relativos à atividade, política esta que tem sido uma constante na empresa". (apud May \& Veiga Neto, 2000, p. 38).

O mesmo pode ser argumentado no que concerne à relação da Cikel Brasil Verde com a Fundação Floresta Tropical, interação apontada pelo diretor-presidente da Cikel como essencial na definição da empresa pela opção da certificação ou pelo papel desempenhado pelas ONGs da 'Aliança para o consumo sustentável' na construção 
de relações (confiáveis) de comércio entre a produção certificada e empresas consumidoras localizadas normalmente no sudeste brasileiro. $^{9}$

Como sublinhamos na introdução, o mercado de madeiras certificadas pode ser compreendido como um marché à prescripteur (Hatchuel, 1995; Aggeri et al., 2005), isto é, um sistema de trocas tornado possível pela participação de um agente/ instituição responsável pela prescrição das qualidades do produto comercializado. Por conseguinte, o elemento central para o estabelecimento da legitimidade da prescrição (Cochoy, 2002, p.79) nesse mercado é a capacidade do agente prescripteur (o FSC) em cumprir os engajamentos que ele associa ao produto certificado.

Quanto ao futuro do mercado de madeiras certificadas, a tendência mais provável é que ele continue se desenvolvendo no segmento das grandes e médias empresas do setor, principalmente naquelas orientadas para o mercado externo ou que fazem parte da global commodity chain (Gereffi, 1994) de madeiras tropicais, contribuindo, portanto, para a formação de um oligopólio de empresas certificadas na Amazônia.

Como já sublinharam outros autores, a possibilidade de ampliação dos efeitos da certificação está relacionada a um outro conjunto de variáveis, que dizem respeito a:

a) aumento efetivo da demanda por madeira certificada no mercado consumidor brasileiro;

b) ampliação da capacidade do Estado em intervir no ordenamento territorial da Amazônia, coibindo o movimento de apropriação irregular de terras e fazendo valer sua autoridade na manutenção da integridade das unidades de conservação; e, 
c) construção de um novo modelo de ocupação e desenvolvimento, de forma a disciplinar o desenvolvimento das principais atividades econômicas regionais (Becker, 2001).

Por fim, deve ser considerado que a certificação de uma empresa não é um processo irreversível, apesar da sugestão dos seus defensores de que a adoção das práticas da EIR levaria a empresa certificada a entrar num círculo virtuoso, ${ }^{10}$ e que os benefícios auferidos com a nova forma de organização da operação florestal levariam à reprodução (inercial) das mesmas. Por conseguinte, creio que devemos considerar a adoção de um certificado ambiental (ou de outra prática associado ao discurso do desenvolvimento sustentável) como o resultado do posicionamento da(s) empresa(s) num dado campo econômico e a capacidade dessa(s) empresa(s) em estabelecer o seu padrão de funcionamento como o padrão hegemônico do funcionamento das empresas do campo.

O caso da empresa Gethal Amazônia, que, após ser adquirida pelo fundo de investimentos Grantham, Mayo, Van Oterlloo \& Co. recebeu alguns aportes de recursos, mas, depois, perdeu o selo do FSC e foi vendida é, a esse respeito, ilustrativo. Mostra a necessidade de relativizar abordagens correntes sobre o processo de adoção de práticas de responsabilidade ambiental e considerar, como aponta a teoria dos campos aplicada à construção de estratégias empresariais, que estas são sempre o resultado de lutas internas às empresas, disputas que geralmente são vencidas por aqueles grupos dirigentes que conseguem impor sua visão de como a firma pode sobreviver em meio à competição no seu mercado específico (Fligstein, 2001, p. 77).

Um outro dado que aponta para a permanência dessas empresas no quadro da certificação está nos preços elevados obtidos pelo produto certificado, fruto, dentre outras coisas, de uma demanda 
bem superior à oferta. Contudo, o que ocorrerá quando essa relação começar a se inverter e os preços iniciarem um processo de queda? Ademais, quais os efeitos que advirão do peso crescente que as importações chinesas - um mercado pouco afeito à sensibilidade ecológica e social - começam a ter sobre as exportações amazônicas? O círculo virtuoso da adoção da tecnologia da EIR será suficiente para mantê-las no campo da boa gestão florestal? Por conseguinte, pensamos que é necessário considerar a construção do mercado de madeiras tropicais certificadas na Amazônia como um processo em aberto, cujo desfecho dependerá da convergência dos esforços realizados pelos seus proponentes e das modificações que porventura venham a ocorrer no quadro institucional da exploração dos recursos florestais na região.

\section{Notas}

1 Existem dois tipos de certificação: a da unidade de manejo florestal e a da cadeia de custódia. Esta última é realizada naquelas indústrias que não possuem áreas próprias de manejo e que compram a madeira que beneficiam de fontes certificadas. A certificação da cadeia de custódia atesta a credibilidade da cadeia de suprimento da floresta à indústria.

2 Vale ressaltar que neste artigo não consideraremos a certificação realizada em regime de manejo florestal comunitário (Carneiro, 2004, p. 216).

3 A madeira certificada é comprada como um bem que presta um serviço, um engajamento: a proteção das florestas tropicais. Como sublinha Karpik (1989, p. 206), essa é uma das dimensões que fundam a economia da qualidade, em contraposição à visão tradicional da economia de bens padronizados.

4 O marché au prescripteur surge naquelas situações em que a dúvida, a desconfiança e a incerteza tornam a relação de troca impossível. "É nesse espaço, entre a troca evidente e a troca impossível que se constitui o lugar do prescripteur" (Hatchuel, 1995, p. 207). 
5 A exploração de impacto reduzido é um padrão tecnológico, isto é, um conjunto de técnicas de exploração florestal desenvolvida em contraposição às técnicas tradicionais, que objetiva conferir maior racionalização, maior eficácia econômica e menor dano ambiental à exploração dos recursos florestais madeireiros em florestas tropicais.

6 A teoria dos campos explica o funcionamento de um dado setor econômico através das relações de concorrência e cooperação entre as empresas situadas no interior desse setor. As empresas dominantes lutam para manter sua posição enquanto as empresas dominadas participam de forma subsidiária ou tentam subverter o status quo do campo (Bourdieu, 2000, p.248).

7 O grupo Gethal surgiu em Caxias do Sul (RS) nos anos 40, dedicado a fabricação de laminados. O deslocamento para a Amazônia está relacionado com a necessidade de suprimento de matéria-prima, dado o esgotamento de suas fontes de suprimento no sul (Zimmermann, 2001, p. 19).

8 Conforme o exemplo paradigmático das ações desenvolvidas pelo Greenpeace sobre o grupo francês Lapeyre, que fez com que essa empresa assumisse o compromisso público de abastecer seu parque industrial com madeira certificada (Carneiro, 2004, p. 70).

9 Como tem sublinhado a literatura sobre o papel das redes no desenvolvimento de instituições econômicas (Granovetter, 1994; Steiner, 1999), o estabelecimento de relações interpessoais entre dirigentes empresariais e entre estes e os líderes de outras instituições importantes para a promoção dos seus negócio, representa um ativo importante para o sucesso dessas firmas.

10 Podemos dizer que a argumentação desenvolvida pelos promotores da certificação é um bom exemplo da adoção como discurso 'nativo' de teses elaboradas no âmbito da teoria evolucionista da firma (Coriat; Weinstein, 1995, p.124), particularmente no que diz respeito ao argumento da dependência da trajetória tecnológica assumida por uma dada empresa. 
The Social Construction of the Brazilian certified wood market in the Amazon Region: the performance of the environmental NGOs and Pioneer Companies

Abstract: This text studies the process of construction of a market for Forest Stewardship Council (FSC) certified timber in the Brazilian Amazon. Forestry certification can be understood as a strategy developed from the 1990s by some environmental non-governmental organizations in an attempt to modify the working patterns of the world timber industry face the relative failure of the previous boycott policy of tropical timber. The process of construction of a market, as shown by several works in economic Sociology, always demand investments that facilitate the mechanism of commodity exchange. We try to show that, in the case of certified timber products, market construction unfolds from the criticism of the traditional market for tropical wood products and from the promotion of mechanisms that supported the growth of certified timber production. We also highlight the trajectory of the first firms who obtained the stamp of forestry certification in order to try to understand the likelihood that this market becomes dominant and therefore redirects forest exploitation in the Amazon towards standards closer to what could be nowadays considered a sustainable activity.

Keywords: Economic Sociology, Sociology of Markets, forest industry, industry and environment, environmentalism, forestry certification, Amazon. 


\section{Referências}

AGGERI, F.; PEZET, E.; ABRASSART, C.; ACQUIER, A. Organiser le développement durable. Paris: Ademe, Vuibert, 2005.

ALMEIDA, Alcir R. C. Experiências da Cikel com o projeto e sugestões para futuras ações. In: CONFERÊNCIA INTERNACIONAL SOBRE MADEIRAS TROPICAIS. Anais da ... Belém, 2002. p. 2528.

AMIGOS DA TERRA; PROGRAMA AMAZÔNIA. Relatório atualizado sobre extração ilegal de madeira na Amazônia Brasileira: garimpagem florestal. São Paulo: Síntese, 1997. 50 p.

AZEVEDO, Tasso R. A novidade: tratar o manejo florestal de forma estratégica e macro. In: BRASIL certificado: a história da certificação florestal no Brasil. Piracicaba: Imaflora, 2005. p.22-26.

BENCHIMOL, Samuel. Exportação da Amazônia Brasileira: 1997. Manaus: Valer, 1998.

BECKER, Bertha K. Revisão das políticas de ocupação da Amazônia: é possível identificar modelos para projetar cenários? Parcerias Estratégicas, n.12, p.135-159, 2001.

BLATE, G.M.; PUTZ, F.E.; ZWEEDE, J.C. Nouvelles pratiques de récolte en Amazonie. Actualités des Forêts Tropicales, v. 9, n. 2, p. 8-9, 2001.

BOYER, Robert. L'anthropologie économique de Pierre Bourdieu. Actes de La Recherche en Sciences Sociales, n.150, p. 65-78, 2003.

BOLTANSKI, L.; CHIAPELLO, E. Le nouvel esprit du Capitalisme. Paris: Galimard, 1999.

BOURDIEU, Pierre. Le champ ecónomique. Actes de la Recherche en Sciences Sociales, n. 119, p. 48-66, 1997.

. Les structures sociales de l'économie. Paris: Éditions du Seuil, 2000 . 
BUCLET, Benjamin. Les expérimentations des ONGs en Amazonie: quel pouvoir pour quelle responsabilité? Lusotopie, n.1, p.263-282, 2002.

CALLON, M.; MUNIESA, F. Les marchés comme dispositifs collectifs de calcul. Réseaux, n. 122, p.189-233, 2003.

CARNEIRO, Marcelo D. S. O dinheiro é verde? A construção social do mercado de madeiras certificadas na Amazônia brasileira. Tese (Doutorado) - Universidade Federal do Rio de Janeiro (UFRJ), 2004.

CARMINO, R. de; ALFARO, M. La certificación en América Latina: experiências hasta la fecha. Red Forestal para el Desarrollo Rural, Documento 23c, 1998.

CLAY, J. W.; AMARAL, P. Madeira tropical sustentável de florestas naturais: o caso da Precious Wood. In: ANDERSON, A.; CLAY, J. (Org.) Esverdeando a Amazônia. São Paulo: Peirópolis, IIEB, 2002. p.163-191.

COCHOY, Franck. Une sociologie du packaging ou l'âne de Buridan face au marché. Paris: PUF, 2002.

CORIAT, B.; WEINSTEIN, O. Les nouvelles theories de l'entreprise. Paris: Le Livre de Poche, 1995.

DELESPINASSE, Bernard. Informação e assistência técnica para a produção e comercialização de madeiras tropicais. In: CONFERÊNCIA INTERNACIONAL SOBRE MADEIRAS TROPICAIS. Anais da... Belém, 2002. p.1-18.

DYKSTRA, Dennis P. L'exploitation à faible impact: l'ancien et le nouveau. Actualités des Forêts Tropicales, v.9, n.2, p.3-4, 2001.

FUNDAÇÃO FLORESTA TROPICAL (FFT). Atuação da Fundação Floresta Tropical no manejo sustentavel da floresta amazonica (19941999). Belém: FFT, 2000.

FLIGSTEIN, Neil. The architecture of markets: an Economic Sociology of $21^{\text {st }}$ Century Capitalist Societies. Princenton: Princenton University Press, 2001. 
GARCIA, Marie-France. La construction sociale d'un marché parfait: le marché au cadran de Fontaines-en-Sologne. Actes de la Recherche en Sciences Sociales, n.65, 1986, p.1-13.

GEREFFI, Gary. The organization of buyer-driven global commodity chains. In: GEREFFI, G.; KORZENIEWICZ, M. (Ed.). Comoddity chains and global Capitalism. Westport: Praeger, 1994. p. 95-122.

GRANOVETTER, Mark. Les institutions économiques comme constructions sociales: un cadre d'analyse. In: ORLÉAN, André. (Dir.). Analyse économique des conventions. Paris: PUF, 1994. p.119-134.

HATCHUEL, Armand. Les marchés à prescripteur. In: JACOB, A.; VÉRIN, H. L'inscription sociale du marché. Paris: L'Harmatan, 1995. p.205-225.

IMAFLORA. Relatório Anual, Plano Estratégico: 1996/1997. Piracicaba: Imaflora, 2000.

KARPIK, Lucien. L'economie de la qualité. Revue Française de Sociologie, v. 30, n.2, p.187-210, 1989.

LEBARON, Fréderic. Le structuralisme génétique. In: BERTHELOT, J-M (Org.). La sociologie française contemporaine. Paris: PUF, 2000. p.59-69.

MACÊDO, A. R. P.; ROQUE, C. A. L.; LEITE, E. T. Produtos sólidos de madeira. In: BNDES setorial, edição especial. 1997. p. 157-176.

MAY, P.H.; VEIGA NETO, F.C. Barreiras à certificação na Amazônia Brasileira: a importância dos custos. Brasília: Pró-Natura, IIED, GTZ, 2002.

PERACCHI, Idacir. Experiências da Juruá com o projeto e sugestões para futuras ações. In: CONFERÊNCIA INTERNACIONAL SOBRE MADEIRAS TROPICAIS. Anais da ... Belém, 2002. p.1-18.

POKORNY, B.; SOUSA, R. Diagnóstico sócio-econômico da indústria madeireira Peracchi, no município de Tailândia, Estado do Pará. Belém: Embrapa, 2000. 
POSTEL, Nicolas. Les règles dans la pensée économique contemporaine. Paris: CNRS Editions, 2003.

PRECIOUS WOOD. Annual Report 2000. Zurich, 2001. . Annual Report 2001. Zurich, 2002. . Annual Report 2002. Zurich, 2003.

SCIENTIFIC CERTIFICATION SYSTEMS (SCS). Sumário público: avaliação de certificação do manejo das florestas naturais da Juruá Florestal Ltda, Fazenda Santa Marta. Piracicaba, 2001.

SMARTWOOD. IMAFLORA. Resumo público de certificação florestal para Gethal Amazonas S/A. Piracicaba, 2000.

. Resumo público de certificação de Lisboa Madeiras Ltda. Piracicaba, 2002.

. Resumo público do monitoramento anual da Gethal Amazonas S/A. Piracicaba, 2004.

SMERALDI, Roberto. Legalidade predatória: o novo quadro da exploração madeireira na Amazônia. São Paulo: Amigos da Terra, Amazônia brasileira, 2002.

SMERALDI, R.; VERISSIMO, A. Acertando o alvo: consumo de madeira no mercado interno e promoção da certificação florestal. São Paulo: Amigos da Terra, 1999.

SMOUTS, Marie-Claude. Forêts tropicales, jungle internationale: le revers de l'ecopolitique mondiale. Paris: Presses de Sciences Po, 2001.

SOBRAL, L.; VERISSIMO, A.; LIMA, E.; AZEVEDO, T.; SMERALDI, R. Acertando o alvo 2: consumo de madeira amazônica e certificação florestal no Estado de São Paulo. Belém: Imazon, 2002.

STONE, Steven W. Tendências econômicas da indústria madeireira no Estado do Pará. Belém: Imazon, 2000. 
STEINER, Philippe. La sociologie économique. Paris: Éditions La Decouverte, 1999.

SWEDBERG, Richard. Une histoire de la sociologie économique. Paris: Desclée de Brouwer, 1994.

UGHETTO, Pascal. Services et construction sociale des marchés. Cahiers Lillois d'Économie \& de Sociologie, n. 41/42, p.57-78, 2003.

VERÍSSIMO, A.; BARRETO, P.; MATOS, M.; TARIFA, R.; UHL, C. Impactos da atividade madeireira e perspectivas para o manejo sustentável da floresta numa velha fronteira da Amazônia: o caso de Paragominas. In: ALMEIDA, O. T. (org.) A evolução da fronteira amazônica. Belém: Imazon, 1996. p.9-37.

VIANA, Virgilio. As florestas brasileiras e os desafios do desenvolvimento sustentável: manejo, certificação e políticas públicas apropriadas. Tese (Livre Docência) - Esalq/USP, 2002.

ZIMMERMANN, Joo. Experiências de manejo florestal sustentável na Amazônia: relatório de missão. Paris: GRET, 2001.

WWF-SUISSE. Certification-Info, n.2, 2002. 